Relations industrielles

Industrial Relations

\title{
Pourquoi nous travaillons. Jean Fourastié. Coll. : Que sais-je? » Presses Universitaires de France, 1959, 126 pp.
}

\section{Gérard Dion}

Volume 14, numéro 3, juillet 1959

URI : https://id.erudit.org/iderudit/1022298ar

DOI : https://doi.org/10.7202/1022298ar

Aller au sommaire du numéro

Éditeur(s)

Département des relations industrielles de l’Université Laval

ISSN

0034-379X (imprimé)

1703-8138 (numérique)

Découvrir la revue

Citer ce compte rendu

Dion, G. (1959). Compte rendu de [Pourquoi nous travaillons. Jean Fourastié. Coll. : Que sais-je? » Presses Universitaires de France, 1959, 126 pp.] Relations industrielles / Industrial Relations, 14(3), 439-439.

https://doi.org/10.7202/1022298ar

Tous droits réservés @ C Département des relations industrielles de l’Université Laval, 1959
Ce document est protégé par la loi sur le droit d'auteur. L’utilisation des services d'Érudit (y compris la reproduction) est assujettie à sa politique d'utilisation que vous pouvez consulter en ligne.

https://apropos.erudit.org/fr/usagers/politique-dutilisation/ 
D'ailleurs, les mots « outsiders 》 et « strangers reviennent fréquemment dans le texte.

Ces débuts conduisaient infailliblenents les opposants à un conflit irréductible. Et l'auteur signale que les propriétaires de l'usine jouissaient de la considération de toute la ville. Ils étaient avantageusement reconnus pour leurs oeuvres de charité, leurs dons généreux à l'Eglise Catholique et leur grande influence dans la vie politique et économique de la Cité. Les travailleurs disaient «the Millers have always run this town ».

La partie la plus intéressante se situe au chapitre 7 intitulé \&Why they strike? » L'auteur signale cependant que les interviews sur cette partie ont été faits après la grève «ended in a claimed union victory $\gg, \infty$ qui peut signifier que les opinions auraient pu être toutes autres en une période différente. Deux points particuliers ressortent de ce chapitre.

1) Une fois de plus il s'agissait d'une grève de reconnaissance syndicale.

2) La ligne de piquetage, attaquée, dans les premiers jours par le Maire de la Ville et la police, devint un symbole et prit une signification prépondérante et décisive pour toute la population.

On ne peut évidemment s'empêcher de faire un parallèle entre cette histoire d'une grève et le volume qui a paru, ici au Canada, il y a quelques années, en marge de la grève de l'amiante.

Certes, le volume du professeur Karsh est beaucoup moins considérable, son optique est de toute évidence plus étroite que celui de l'équipe «Cité libre», mais on peut quand même signaler que si quelques sociologues ou chercheurs s'avisaient de faire de chacune de nos grèves de quelque importance. un genre d'étude comme celle du professeur Karsh, notre littérature si pauvre en ce domaine, s'enrichirait d'une véritable enthologie sociale extrêmement utile voire essentielle, car comme le dit l'auteur \& a labor strike is one of the most highy publicised but least studied social phenomena of our time ».

Jacques Archambault
Pourquoi nous travaillons. Jean Fourastié. Coll. : Que sais-je? 》 Presses Universitaires de France, 1959, 126 pp.

Voici un petit ouvrage qui répond à un besoin et qui rendra de grands services. La science économique a pris un essor considérable en ces dernières années, bien qu'elle reste encore loin d'être capable de résoudre tous les problèmes. «Nulle part, plus qu'en économie, l'ignorance n'enveloppe l'humanité ». Cependant qui ne cherche pas à comprendre un peu le monde dans lequel il vit et les foroes qui influencent son destin. Par ailleurs dans les écoles on n'y enseigne à peu près rien. Et il est assez difficile pour un débutant de se lancer dans de profonds traités techniques où il serait facilement perdu. "Le but de ce livre, dit l'auteur, est de mettre à la portée du Français moyen oe qui me paraît être, à l'heure où j'écris, les bases élémentaires d'une science économique concrète, c'est-àdire utile à l'homme d'action et apte à faire mieux comprendre à l'homme de pensée les réalités du monde où il vit. Plus précisément, ce livre s'adresse aux autodidactes ».

Même si les données de bases d'où part l'auteur pour illustrer ses exposés sont tirées de la réalité française, cet ouvrage peut être très utile aux Canadiens, car ils pourront facilement effectuer les transpositions nécessaires. Après une introduction où l'auteur nous fait passer de la réalité quotidienne à la science économique, six chapitres viennent nous présenter les principaux problèmes de l'économique: Pourquoi nous travaillons; Comment nous travaillons; Le rationnement et les revenus; Les revenus et les prix; L'emploi et les salaires; Le salaire indirect; La sécurité sociale; Niveau de vie, genre de vie.

G.D.

L'Action sociale des catholiques en France (1871-1914), par Henri Rollet, tome second. Desclée de Brouwer, Paris, 1958, 404 pp.

Dans ce tome second l'auteur, un chercheur consciencieux, a relevé et raconté tout ce que les catholiques de France ont fait ou tenté de faire dans 